University of Wollongong

Research Online

Faculty of Engineering and Information

Faculty of Engineering and Information

Sciences - Papers: Part B

Sciences

2016

\title{
A New Torque Distribution Strategy for Blended Anti-Lock Braking Systems of Electric Vehicles Based on Road Conditions and Driver's Intentions
}

Wenfei Li

University of Wollongong,w1015@uowmail.edu.au

Haiping Du

University of Wollongong, hdu@uow.edu.au

Weihua Li

University of Wollongong, weihuali@uow.edu.au

Follow this and additional works at: https://ro.uow.edu.au/eispapers1

Part of the Engineering Commons, and the Science and Technology Studies Commons

Research Online is the open access institutional repository for the University of Wollongong. For further information contact the UOW Library: research-pubs@uow.edu.au 


\title{
A New Torque Distribution Strategy for Blended Anti-Lock Braking Systems of Electric Vehicles Based on Road Conditions and Driver's Intentions
}

\begin{abstract}
This paper proposes a new braking torque distribution strategy for electric vehicles equipped with a hybrid hydraulic braking and regenerative braking system. The braking torque distribution strategy is proposed based on the required braking torque and the regenerative braking system's status. To get the required braking torque, a new strategy is designed based on the road conditions and driver's braking intentions. Through the estimated road surface, a robust wheel slip controller is designed to calculate the overall maximum braking torque required for the anti-lock braking system (ABS) under this road condition. Driver's braking intentions are classified as the emergency braking and the normal braking. In the case of emergency braking, the required braking torque is to be equal to the overall maximum braking torque. In the case of normal braking, the command braking torque is proportional to the pedal stroke. Then the required braking torque is chosen as the smaller one between the overall maximum braking torque and the command braking torque. To acquire both high regenerative efficiency and good braking performance when the required braking torque is smaller than the maximum braking torque of the regenerative braking system, the whole braking torque can be provided by the regenerative braking system; when the required braking torque is bigger than the maximum braking torque of the regenerative braking system, the whole braking torque can be provided by both the hydraulic braking system and the regenerative braking system, while the maximum braking torque of the regenerative braking system is obtained based on the battery state of charge (SOC) and vehicle speed in real-time. Both fuzzy rule-based scheduling and robust control approaches will be applied to achieve the above proposed distribution strategy. The effectiveness of the proposed control system is validated by numerical simulations under various road conditions, vehicle speeds, driver's braking intentions, and the battery SOCs.

\section{Disciplines}

Engineering | Science and Technology Studies

\section{Publication Details}

W. Li, H. Du \& W. Li, "A New Torque Distribution Strategy for Blended Anti-Lock Braking Systems of Electric Vehicles Based on Road Conditions and Driver's Intentions," SAE International Journal of Passenger Cars: Mechanical Systems, vol. 9, (1) pp. 107-115, 2016.
\end{abstract}




\title{
A New Torque Distribution Strategy for Blended Anti-Lock Braking Systems of Electric Vehicles Based on Road Conditions and Driver's Intentions
}

\author{
Wenfei Li, Haiping Du, and Weihua Li \\ University of Wollongong
}

\begin{abstract}
This paper proposes a new braking torque distribution strategy for electric vehicles equipped with a hybrid hydraulic braking and regenerative braking system. The braking torque distribution strategy is proposed based on the required braking torque and the regenerative braking system's status. To get the required braking torque, a new strategy is designed based on the road conditions and driver's braking intentions. Through the estimated road surface, a robust wheel slip controller is designed to calculate the overall maximum braking torque required for the anti-lock braking system (ABS) under this road condition. Driver's braking intentions are classified as the emergency braking and the normal braking. In the case of emergency braking, the required braking torque is to be equal to the overall maximum braking torque. In the case of normal braking, the command braking torque is proportional to the pedal stroke. Then the required braking torque is chosen as the smaller one between the overall maximum braking torque and the command braking torque. To acquire both high regenerative efficiency and good braking performance when the required braking torque is smaller than the maximum braking torque of the regenerative braking system, the whole braking torque can be provided by the regenerative braking system; when the required braking torque is bigger than the maximum braking torque of the regenerative braking system, the whole braking torque can be provided by both the hydraulic braking system and the regenerative braking system, while the maximum braking torque of the regenerative braking system is obtained based on the battery state of charge (SOC) and vehicle speed in real-time. Both fuzzy rule-based scheduling and robust control approaches will be applied to achieve the above proposed distribution strategy. The effectiveness of the proposed control system is validated by numerical simulations under various road conditions, vehicle speeds, driver's braking intentions, and the battery SOCs.
\end{abstract}

CITATION: Li, W., Du, H., and Li, W., "A New Torque Distribution Strategy for Blended Anti-Lock Braking Systems of Electric Vehicles Based on Road Conditions and Driver's Intentions," SAE Int. J. Passeng. Cars - Mech. Syst. 9(1):2016, doi:10.4271/2016-01-0461.

\section{INTRODUCTION}

As a crucial part of vehicles, the anti-lock braking system (ABS) plays an important role for improving vehicle braking performance in emergency situations. The ABS not only can keep the wheel directional control but also can reduce the stop distance in severe braking. The key part of ABS is the wheel slip ratio control. In order to acquire the maximum friction force and the shortest braking distance, ABS should be able to keep wheel slip ratio track the optimum of slip ratio under given road conditions. In conventional hydraulic braking (HB) system, the most common ABS algorithm is based on the logic threshold control (LTC) through monitoring deceleration and slip ratio of wheels [1]]. In order to track the optimal slip ratio, many other algorithms are also used, such as sliding mode control [ㄹ] , adaptive control, neural control []ㅡ, fuzzy control [ $\underline{4}]$ and so on. However, due to the slow dynamic characteristics of the hydraulic system, the friction braking torque has a significant delay during a transient response and it seriously affects the optimal slip ratio control performance [ $\underline{5}]$.

Electric vehicles are currently received much attention due to their zero carbon dioxide emission and other advantages compared to conventional engine vehicles []․ Electric vehicles can normally be equipped with regenerative braking (RB) system [7] in addition to the $\mathrm{HB}$ system. As $\mathrm{HB}$ system can provide large braking torque and $\mathrm{RB}$ system has fast response, which is beneficial to the wheel slip ratio control in an emergency braking, appropriate control of these two braking systems not only can enhance the braking performance but also can improve energy regeneration. Therefore, blended braking system that combines conventional $\mathrm{HB}$ system and $\mathrm{RB}$ system is becoming more attractive and the coordination between energy recovery and vehicle stability through distributing braking torque between the RB system and conventional $\mathrm{HB}$ system have received more attention []ㅡ. In []ㅡ, the authors conducted a research on braking performance in emergency braking, where the HB system generates a stable pressure which is equal to the required torque, and the RB system is used as an auxiliary system to improve the dynamic characteristics of the braking system. In [1] , the energy recovery of a braking system was focused on. For achieving the maximum energy recovery, the $\mathrm{HB}$ system is preferred not to operate until the $\mathrm{RB}$ system reaches its maximum availability. This strategy can improve the energy recovery performance. However, in emergency situation, the braking performance will be affected. For getting a good braking performance and high energy recovery, it is necessary to take different distribution strategies based on different conditions. For 
example, the braking torque distribution strategy can be changed based on different braking modes [] $]$. Nevertheless, just considering the braking modes is not enough for accurate control. It is necessary to take driver's braking intention, the relationship between pedal displacement and braking force, road condition and vehicle status into consideration.

In this paper, we design a new torque distribution strategy for blended ABS. A three-point prediction method is utilized to estimate the road surface [9] and a robust wheel slip ratio control [ $\underline{5}$ ] is used to calculate the overall maximum braking force based on road conditions. The driver's braking intention is identified by a fuzzy system [17]. And the relationship between pedal displacement and braking force is also considered in braking condition [10]. The effectiveness of the proposed control system is validated by numerical simulations under various conditions. The main contribution of the paper is to develop a relationship between pedal commander and braking force by combining driver's braking intention and pedal displacement. And a torque distribution strategy is developed based on driver's braking intention, pedal displacement, road condition, battery state, motor and vehicle status.

The rest of the paper is organized as follows. In Section 2, the models of whole system including quarter-vehicle dynamics, HB system, RB system, the fuzzy system which is used to identify driver's braking intention, relationship between pedal stroke and braking force are introduced. In $\underline{\text { Section } 3}$, the supervisory slip controller is discussed. It includes a three-point prediction method and a robust wheel slip ratio controller. The torque distribution strategy is discussed in $\underline{\text { Section } 4}$. In Section 5 , the simulation results on a quarter-vehicle braking model are presented. Finally, conclusions are given in Section 6.

\section{SYSTEM MODELING}

\section{Vehicle Dynamics Model}

In this section, a quarter-vehicle model is used in this paper [11]. This model can be presented by a single wheel. As most ABS control strategies [11] did, only a straight-line braking event is considered in this study and the wheel viscous friction forces are ignored. The dynamics of the vehicle and wheel model can be expressed as:

$$
\begin{gathered}
\mathrm{J} \omega_{w}=-T_{b}+r F_{x} \\
\mathrm{~m} \dot{v}=-F_{x}-F_{a} \\
F_{a}=f_{a} v^{2} \\
F_{x}=\mu(\lambda) m g \\
\lambda=\frac{\omega_{v}-\omega_{\omega}}{\omega_{v}}
\end{gathered}
$$

where $r$ is the effective wheel radius, $\mathrm{J}$ is the moment of inertia of the wheel, $T_{b}$ is the braking torque, $v$ is the longitudinal velocity of the vehicle, $\omega_{w}$ is the angular velocity of the wheel, $\omega_{v}$ is the angular velocity of the vehicle, which can be measured by dual-antenna global positioning system [ $[\underline{]}], F_{x}$ is the longitudinal tire force, $\mathrm{m}$ is total mass of the quarter vehicle, $f_{a}$ is the aerodynamic drag coefficient, $F_{a}$ is the aerodynamic drag force, $\mu(\lambda)$ is the tyre longitudinal friction coefficient, which is a function of wheel slip ratio $\lambda$. In this paper, the tire model used is based on the tire friction model developed by Burckhardt and Reimpell (1993). It is shown as below [11]:

$$
\mu(\lambda)=C_{1}\left(1-e^{-c_{2} \lambda}\right)-C_{3} \lambda
$$

where $C_{1}, C_{2}$ and $C_{3}$ are constants for different road conditions. $C_{1}$ is the maximum value of the friction curve, $C_{2}$ indicates the friction curve shape and $C_{3}$ is the difference between the peak value of the friction curve and the value when slip ratio is 1 .

\section{Hydraulic Braking System Model}

In this paper, $\mathrm{HB}$ system is described by the following equation [11]:

$$
d p_{w} / d t=\frac{k_{1} C_{d} A_{v i} k}{V_{0}}\left(p_{m}-p_{w}\right)^{\varphi_{i}}-\frac{k_{2} C_{d} A_{v d} k}{V_{0}}\left(p_{w}-p_{0}\right)^{\varphi_{d}}
$$

where $k_{1}, k_{2}$ represent the control signals to simulate the on-off feature of the pressure modulation for the wheel cylinder, where the states of $\mathrm{HB}$ system can be classified into three modes: increasing, decreasing and holding. $p_{w}, p_{m}, p_{0}$ are wheel cylinder pressure, master cylinder pressure and reservoir pressure. $C_{d d^{r}} A_{v}, A_{v d} k$ and $V_{0}$ are the flow coefficient of the valves, the cross-sectional area of the inlet valves, the cross-sectional area of the outlet valves, the bulk modulus of the brake oil and the brake oil volume under no pressure, respectively. $\varphi_{i}$ and $\varphi_{d}$ are the coefficients for pressure increasing and decreasing modes, respectively, and they can be calibrated from experimental data [2] as following:

$$
\frac{d p_{w}}{d t}=\left\{\begin{array}{cl}
37.5416 *\left(p_{m}-p_{w}\right)^{0.59} & \text { Increasing } \\
0 & \text { Holding } \\
-38.3128 *\left(p_{w}-p_{0}\right)^{0.93} & \text { Decreasing }
\end{array}\right.
$$

The $\mathrm{HB}$ torque can then be calculated using the following equation:

$$
T_{h b}=2 P_{w} A_{w} f_{h b} r_{h b}
$$

where $T_{h b}$ is the hydraulic brake torque, $A_{w}$ is wheel cylinder cross sectional area, $f_{h b}$ is the friction coefficient, $r_{h b}$ is the effective brake radius. 


\section{Regenerative Braking System}

In this paper, the RB system consists of in-wheel motors and battery pack. Detailed characteristics descriptions of the RB system can be found in reference [] ]. The maximum braking torque of motor can be described by following equation []]:

$$
T_{\max }= \begin{cases}T_{m N} & \omega_{w}<\omega_{m N} \\ 9550 P_{m N} / \omega_{m} & \omega_{w}>\omega_{m N}\end{cases}
$$

where $T_{\max }$ is the maximum motor torque, $T_{m N}$ is the motor rated torque, $\omega_{w}$ is the motor speed, $\omega_{m N}$ is the motor base speed and $P_{m N}$ is the motor rated power.

Considering battery overcharging may shorten the battery's life when the battery SOC is high, a weighting factor $W_{S O C}$ is employed to protect the battery. So the motor available braking torque is written as follow:

$$
T_{\text {avail }}=T_{\max } W_{S O C}
$$

The weighting factor for the battery SOC can be written as follows:

$$
W_{\text {SOC }}=\left\{\begin{array}{cc}
1 & S O C_{a c t}<0.8 \\
1-S O C_{a c t} & 0.8 \leq S O C_{a c t}<0.9 \\
0 & S O C_{\text {act }} \geq 0.9
\end{array}\right.
$$

where $S O C_{a c t}$ can be written as follows:

$$
S O C_{a c t}=S O C_{i n i}-\frac{100 \int_{0}^{t} I(\tau) d \tau}{Q_{c}}
$$

where $S O C_{a c t}$ is the actual battery SOC value; $S O C_{i n i}$ is the initial battery SOC value; $Q_{C}$ is the total battery energy capacity; $I$ is the motor current:

$$
I=\frac{U}{R_{\text {chg }}}
$$

where $\mathrm{U}$ is the battery charging voltage, and it can be written as follows:

$$
\mathrm{U}=\frac{V_{o c}-\sqrt{V_{o c}^{2}+4 P_{\text {motor }} R_{\text {chg }}}}{2}
$$

where $V_{o c}$ is the open-circuit voltage which is the terminal voltage at zero current flowing in or out the battery. $R_{\text {chg }}$ is internal resistance value, it depends on the state of the battery. The power into the motor $P_{\text {motor }}$ can be calculated as

$$
P_{\text {motor }}=T_{r b} \omega_{w} \rho
$$

where $P_{\text {motor }}$ is the power generated by regenerative braking system; $T_{r b}$ is the actual regenerative braking torque; $\rho$ is the power efficiency.

\section{Pedal Simulator}

In the brake-by-wire system, the brake pedal is not directly connected to the actuators. So a pedal simulator is needed to simulate the traditional braking system. In this paper, the model of pedal simulator is described by the following functions [10]:

$$
P_{m}=a_{1} V^{2}+a_{2} V
$$

where $\mathrm{V}$ is the volume of brake fluid pushed; $a_{1}, a_{2}$ are fitting factors.

$$
V=A_{p} x
$$

where $A_{\mathrm{p}}$ is the piston area; $\mathrm{x}$ is the piston displacement. The relationship between piston displacement $\mathrm{x}$ and the piston force $\mathrm{N}$ can be described as:

$$
\mathrm{N}=a_{1} A_{p}^{3} x^{2}+a_{2} A_{p}^{2} x
$$

The relationship between pedal stroke $\mathrm{L}$ and piston displacement $\mathrm{x}$ can be written as:

$$
\mathrm{L}=\beta x
$$

where $\mathrm{L}$ is pedal stroke; $\beta$ is leverage ratio; $\mathrm{L}_{\max }$ is the maximum stroke of pedal. Finally, the relationship between pedal stroke $\mathrm{L}$ and the master cylinder pressure $P_{m}$ can be written as:

$$
P_{m}=\frac{a_{1} A_{p}^{2} L^{2}}{\beta^{2}}+\frac{a_{2} A_{p} L}{\beta}
$$

when $\mathrm{L}=\mathrm{L}_{\max }$ :

$$
\begin{gathered}
P_{\text {mmax }}=\frac{a_{1} A_{p}^{2} L_{\text {max }}^{2}}{\beta^{2}}+\frac{a_{2} A_{p} L_{\max }}{\beta} \\
T_{c b}=T_{h \max }=2 P_{\text {max }} A_{w} f_{h b} r_{h b}
\end{gathered}
$$

where $T_{\text {hmax }}$ is the maximum braking torque of the HB system. In this paper, $T_{\text {max }}$ is $400 \mathrm{Nm} . T_{c b}$ is the command braking torque. $T_{c b}$ can be calculated by following equation:

$$
T_{c b}=2 P_{m} A_{w} f_{h b} r_{h b}
$$

\section{Driver's Braking Intentions}

In this paper, the driver's braking intentions are classified as emergency braking and normal braking. In [17], the ANFIS has been used to identify driver's braking intentions through 1200 sets of data. Referring to [17], we build a TS-fuzzy system to identify driver's braking intentions. The inputs of the fuzzy system are pedal stroke and the change rate of the pedal stroke. Three linguistic values are 
used to describe pedal stroke and the change rate of the pedal stroke. They are $\mathrm{S}=\mathrm{Small}, \mathrm{M}=\mathrm{Medium}, \mathrm{B}=\mathrm{Big}$. The membership functions of these two variables are shown in Fig. 1. [17].
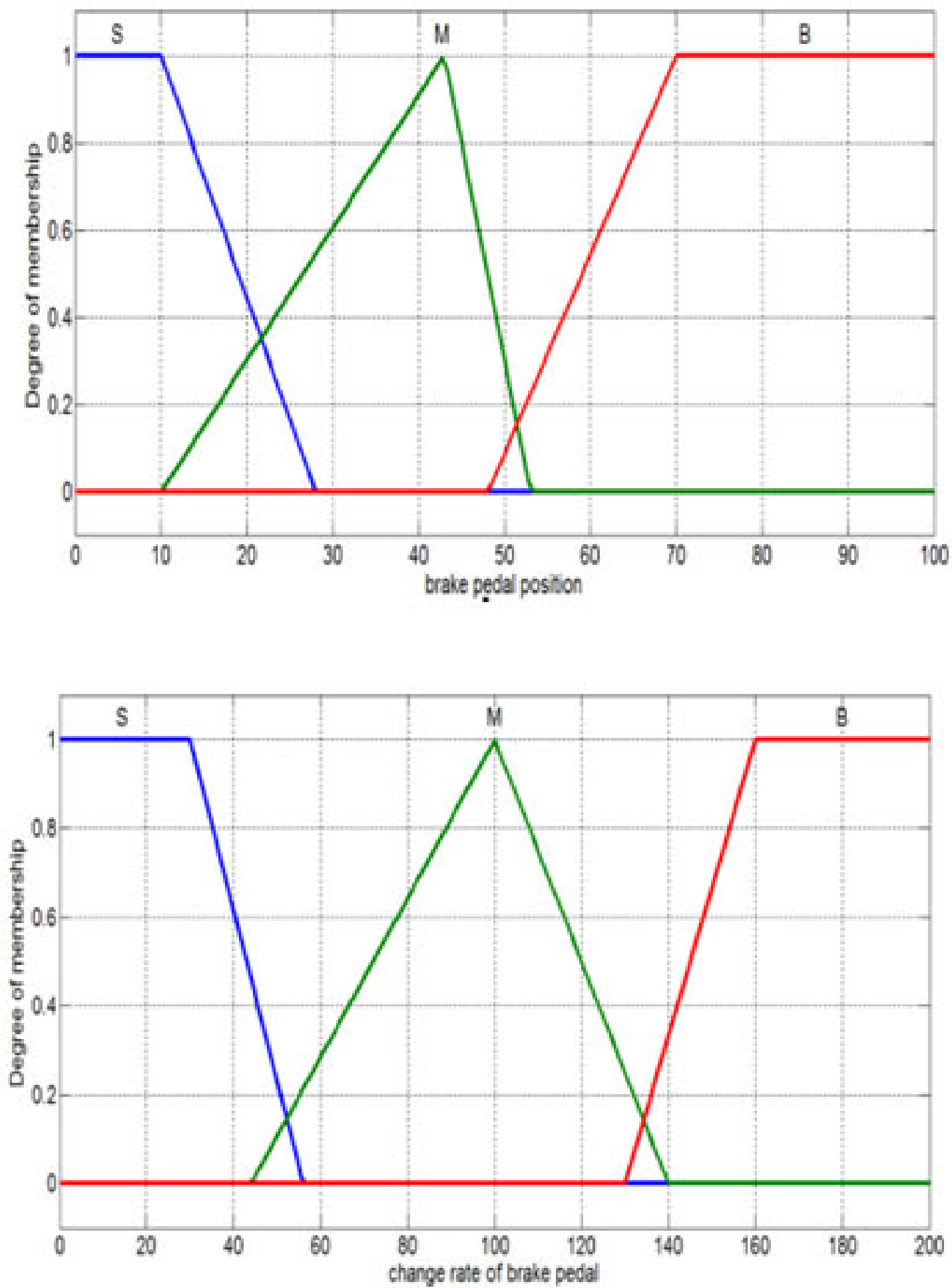

Figure 1. Membership functions of pedal stroke and the change rate of the pedal stroke.

The output of the fuzzy system is the driver's braking intention. It can be divided as normal braking $(\mathrm{NB})$ and emergency braking $(\mathrm{EB})$. When braking intention is normal braking, output of fuzzy system is constant 1 . When braking intention is emergency braking, output of fuzzy system is constant 2 . And the fuzzy rules are defined in Table 1.

Table 1. Fuzzy rule

\begin{tabular}{c|c|c|c}
\hline \multirow{2}{*}{$\begin{array}{c}\text { the change rate of } \\
\text { the pedal stroke }\end{array}$} & \multicolumn{3}{|c}{ pedal stroke } \\
\cline { 2 - 4 } & $\mathrm{S}$ & $\mathrm{M}$ & $\mathrm{B}$ \\
\hline $\mathrm{S}$ & $\mathrm{NB}$ & $\mathrm{NB}$ & $\mathrm{NB}$ \\
\hline $\mathrm{M}$ & $\mathrm{NB}$ & $\mathrm{NB}$ & $\mathrm{EB}$ \\
\hline $\mathrm{B}$ & $\mathrm{EB}$ & $\mathrm{EB}$ & $\mathrm{EB}$ \\
\hline
\end{tabular}

\section{DESIGN OF SUPERVISORY CONTROLLER}

The supervisory slip controller is made up of an optimal slip ratio estimation and a robust wheel slip ratio controller.

\section{Three-Point Prediction Method}

In this paper, a three-point prediction algorithm is used to estimate the optimal slip ratio. From [11], we can see that optimal slip ratio can be given by $\lambda_{\mu \max }=\ln \left(c_{1} c_{2} / c_{3}\right) / c_{2}$. At first, the algorithm tests the deceleration at three different predefined slip ratios and uses these values to predict the surface characteristics. Each surface can be defined by the equation (6). From equation (6), we can see that if the values of $c_{1}, c_{2}$ and $c_{3}$ are known, the peak slip can be located. These three parameters can be derived as:

$$
\begin{gathered}
c_{1}=\frac{\mu\left(\lambda_{1}\right) \lambda_{2}-\mu\left(\lambda_{2}\right) \lambda_{1}}{\lambda_{2}-\lambda_{2}} \\
c_{3}=\frac{\mu\left(\lambda_{1}\right)-\mu\left(\lambda_{2}\right)}{\lambda_{2}-\lambda_{2}} \\
c_{2}=\frac{\ln \left(c_{1} /\left(c_{1}-\mu\left(\lambda_{3}\right)-c_{3} \lambda_{3}\right)\right)}{\lambda_{3}}
\end{gathered}
$$

where $\lambda_{1}, \lambda_{2}$ and $\lambda_{3}$ are three slip ratio constants to be chosen to estimate $c_{1}, c_{2}$ and $c_{3}$. According to [ 6 ], the three constants can be chosen as $0.6,0.5$ and $0.1 . \mu\left(\lambda_{1}\right), \mu\left(\lambda_{2}\right)$ and $\mu\left(\lambda_{3}\right)$ are the coefficients of friction at the respective slip ratios.

\section{Robust Wheel Slip Ratio Controller}

In this paper, the main objective of the robust slip ratio controller is to deal with the modelling errors and provide the overall maximum braking torque required for the ABS under given road conditions. According [ 1$]$ - [ $\underline{5}]$, the dynamic models of a quarter-vehicle can be rewritten as:

$$
\begin{gathered}
\dot{\lambda}=f(X)+b u(t) \\
\mathrm{y}=\lambda
\end{gathered}
$$

where

$$
\begin{gathered}
f(\mathrm{X})=\frac{1}{\omega_{v}(t)}\left\{\left[-\frac{g}{r}\left(1-\lambda(t)-\frac{r}{J} m g\right] \mu(\lambda)+(\lambda(t)-1) \frac{f_{a} r}{m} \omega_{v}^{2}(t)\right\}\right. \\
\mathrm{b}=\frac{1}{\omega_{v}(t) J} \\
\mathrm{u}(\mathrm{t})=T_{t r b}(t)
\end{gathered}
$$

where $T_{t r b}$ is the the total required braking torque for the ABS to track the optimal slip ratio under related road condition. In order to improve the optimum slip ratio tracking, an optimal predictive control (OPC) is used in this paper. The main idea is explained as follows []ㅡ: The wheel slip of the next time $\lambda(\mathrm{t}+\mathrm{h})$ is first approximated by truncating the Taylor expansion up to the first order term:

$$
\lambda(\mathrm{t}+\mathrm{h})=\lambda(\mathrm{t})+h[\dot{e}(t)+\dot{\lambda}(t)]
$$


where $h$ denotes the predictive period; $\mathrm{e}(\mathrm{t})=\lambda(t)-\lambda_{d}(t) ; \lambda_{d}(t)$ is the desired slip ratio which is equal to $\lambda_{\mu \max }$. For reducing the slip tracking error with the minimum control effort, a cost function is designed as follows:

$$
\begin{aligned}
\mathrm{J}=\frac{1}{2} & \tau_{1}\left[\lambda(t+h)-\lambda_{d}(t+h)\right]^{2}+\frac{1}{2} \tau_{2} u(t)^{2} \\
& =\frac{1}{2} \tau_{1}\left[e(t)+h\left(f(X)-\dot{\lambda}_{d}(t)\right)+h b u(t)\right]^{2}+\frac{1}{2} \tau_{2} u(t)^{2}
\end{aligned}
$$

where $\tau_{1}>0, \tau_{2}>0$ are weighting factors. In real applications, $f(X)$ and $b$ is hard to be acquired. For controller design, their estimated values $\hat{f}(X)$ and $\hat{b}$ are used. The optimality for the cost function is obtained by using $\partial J / \partial u=0$, then:

$$
\mathrm{u}(\mathrm{t})=-\frac{h \hat{b}}{h^{2} \hat{b}^{2}+\eta}\left[e(t)+h\left(\hat{f}(X)-\dot{\lambda}_{d}(t)\right)\right]
$$

where $\eta=\tau_{2} / \tau_{1}$;

To deal with estimated error, robust controller is used in this paper. In the following, the design of a robust controller is introduced. First, some assumptions are presented [ㄷ]:

\section{Assumption 1}

The parameters of uncertainties have known bounds, which yields:

$$
|f(X)| \leq \zeta \alpha^{T} \beta(t)
$$

where

$$
\begin{gathered}
\alpha^{T}=\left[\begin{array}{lll}
\frac{f_{a} r}{m} & \frac{g}{r} & \frac{m g r}{J}
\end{array}\right] \\
\beta^{T}(t)=\left[\left|\omega_{v}(t)(1-\lambda)\right|\left|\frac{\mu(\lambda)(1-\lambda)}{\omega_{v}(t)}\right|\left|\frac{\mu(\lambda)}{\omega_{\nu}(t)}\right|\right] \\
\zeta \geq \zeta_{0}=\hat{J} / J
\end{gathered}
$$

\section{Assumption 2}

Control input is assumed to be bounded:

$$
|f(X)-\dot{\lambda}| \leq P
$$

where $\mathrm{P}$ is a positive constant.

\section{Assumption 3}

The estimated error between $\hat{f}(X)$ and $f(X)$ is assumed to be bounded by a positive constant $\Psi$

$$
|f(X)-\hat{f}(X)| \leq \Psi
$$

Now we define $\xi=h b /\left(h^{2} \hat{b}^{2}+\eta\right)$, In order to ensure the stability, selecting a Lyapunov function candidate as:

$$
\mathrm{V}(\mathrm{t})=\frac{1}{2}\left(\lambda(t)-\lambda_{d}(t)\right)^{2}
$$

Its time derivative:

$$
\dot{V}(t)=e \dot{e}=-\frac{e^{2}}{h}+e\left[\left(\frac{1}{\xi \hat{b} h}-1\right)(f(X)-\dot{\lambda})+(f(X)-\hat{f}(X))\right]
$$

In order to ensure $V(t) \leq 0$, wheel slip tracking error should be limited to a bounded range between $\pm[h \psi+h \mathrm{P}(1 / \xi \hat{b} \mathrm{~h}-1)]$. In order to reduce the tracking error, it should make $\xi=\hat{b} h$. Then, wheel slip tracking error converges to $\pm h \psi$. For a certain road condition, the target slip ratio is a constant, so $\dot{\lambda}_{d}=0$. then (35) can be written as:

$$
\mathrm{u}(\mathrm{t})=-\frac{1}{h \hat{b}} e-\frac{\hat{f}(X)}{\hat{b}}
$$

From above analysis, the wheel slip tracking error will be limited to a bounded range between $\pm h \psi$. To make the tracking error converge to zero, a feedback compensation term $u_{f d}$ is designed:

$$
\mathrm{u}(\mathrm{t})=-\frac{1}{h \hat{b}} e+\frac{u_{f d}}{\hat{b}}
$$

then derivative of Lyapunov function (43) can be written as:

$$
\dot{V}(t)=-\frac{e^{2}}{h} \zeta_{0}+e\left[f(X)+u_{f d} \zeta_{0}\right]
$$

To ensure $\dot{V}(t) \leq 0$ we select:

$$
u_{f d}=-\hat{\alpha}^{T} \beta(t) \operatorname{sgn}(e)
$$

where $\hat{a}$ denotes the estimate vector set of $\alpha$. It consists of the estimate vehicle parameters with each element $\hat{a}_{i}>\alpha_{i}>0$. And the control input can be written as:

$$
\mathrm{u}(\mathrm{t})=-\frac{1}{h \hat{b}} e-\hat{\theta}^{T} \delta(t) \operatorname{sgn}(e)
$$

where:

$$
\hat{\theta}_{i}=\hat{\alpha}_{i} \hat{j}
$$

$$
\delta^{T}(t)=\left[\omega_{v}^{2}|1-\lambda||\mu(\lambda)(1-\lambda)||\mu(\lambda)|\right]
$$


Then, the overall maximum braking torque required for the $\mathrm{ABS}$ under given road condition is calculated based on (48).

\section{BRAKING TORQUE DISTRIBUTION STRATEGY}

The whole structure of vehicle braking system is shown in Fig.2. The role of each part will be introduced as below. First, based on pedal command, driver's braking intentions can be identified by the fuzzy system which is introduced in Section 2 . The supervisory slip controller is used to calculate the total required braking torque for the ABS to track the optimal slip ratio under related road condition. Based on equation (48), total required braking torque can be calculated. The supervisory slip controller can work on two different states based on driver's braking intentions. When driver's braking intention is emergency braking, the supervisory slip controller will be directly used to control whole vehicle brake system. When driver's braking intention is normal braking, the supervisory slip controller will monitor the vehicle's slip. In this case, if $T_{t r b}<T_{c b}$, the supervisory slip controller will be directly used to control whole vehicle brake system. If $T_{t r b}>T_{c b}$, the braking torque will track $T_{c b}$. Based on SOC and wheel speed, motor and battery can provide the maximum available braking torque $\left(T_{\text {avail }}\right)$ of RB system through equation (11). Based on driver's braking intention, $T_{c b}, T_{t r b}$ and $T_{\text {avail }}$, torque allocator is used to allocate braking torque to $\mathrm{HB}$ and $\mathrm{RB}$ systems. The details of torque allocator will be introduced in the next paragraph. $\mathrm{HB}$ actuator and $\mathrm{RB}$ actuator are used to impose braking torque to vehicle and make vehicle stop.

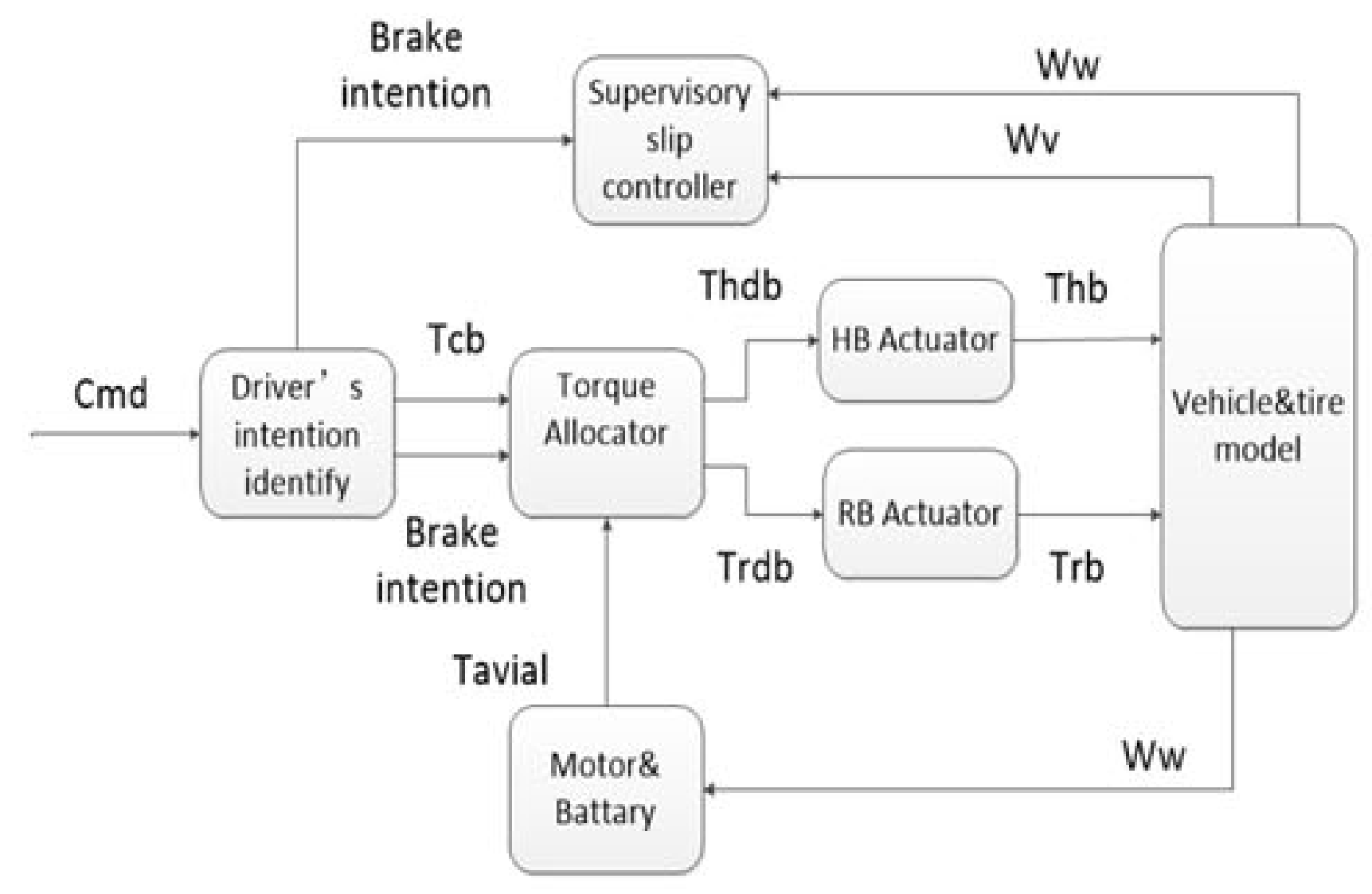

Figure 2. Whole structure of the braking control system.

When the brake action is taken, the overall required braking torque of whole vehicle system $\left(T_{o r b t}\right)$ should first be calculated. $T_{\text {orb } t}$ is the sum of the desired HB torque $\left(T_{h d b}\right)$ and the desired RB torque $\left(T_{r a b}\right): T_{o r b t}=$ $T_{h d b}+T_{r d b} \cdot T_{o r b t}$ is determined based on pedal stroke, change rate of the pedal stroke, driver's braking intention and supervisory slip controller. Its value can be divided into the following three situations. If driver's braking intention is emergency braking, supervisory slip controller will be used to control whole brake system and $T_{t r b}$ will be used as $T_{o r b t}$ : $T_{o r b t}=T_{t r b}$. If driver's braking intention is normal braking and $T_{c b}<$ $T_{t r b}$, in this situation, the overall required braking torque will track command braking torque: $T_{o r b t}=T_{c b}$. If driver's braking intention is normal braking and $T_{c b}>T_{t r b}, T_{t r b}$ will be used as $T_{o r b t}: T_{o r b t}=T_{t r b}$. Then, $T_{\text {orbt }}$ is allocated to $\mathrm{HB}$ actuator and $\mathrm{RB}$ actuator.
We design a brake torque distribution strategy based on following principles: during emergency braking, braking performance is more important than energy recovery. And during normal braking, distribution strategy should pay more attention to energy recovery. The strategy is: In emergency braking, if $T_{\text {orbt }}<T_{\text {avail }}$, RB system can meet the required braking torque of whole brake system. So only RB system works: $T_{r a b}=T_{o r b t}$. In this case, Braking performance can be guaranteed and energy recovery is maximized. If $T_{\text {orbt }} \geq T_{\text {avail }}, \mathrm{RB}$ system and $\mathrm{HB}$ system will work together and $\mathrm{HB}$ system is used to track $T_{\text {orbt }}: T_{h d b}=T_{\text {orbr }}$, the RB system is used to eliminate the error between $T_{h d b}$ and $T_{h b}$ caused by slow dynamic characteristics of the hydraulic system and other uncertain factors. In this case, although energy recovery is not maximized, braking performance can be guaranteed. This is in accordance with the principle of emergency braking. In normal braking, if $T_{\text {orbt }} \leq T_{\text {avail }}, \mathrm{RB}$ system can meet the required braking torque of whole brake system. So only RB system works: $T_{r a b}=T_{o r b t}$. In this case, Braking performance can be guaranteed and energy recovery is maximized. If $T_{\text {orbt }} \geq T_{\text {avail }}, \mathrm{RB}$ system and $\mathrm{HB}$ system will work together. Based on the principle of energy recovery is more important than braking performance in normal braking, Braking torque can be assigned as: $T_{r d b}=T_{a v a i l}, T_{h d b}=$ $T_{\text {orbt }}-T_{\text {avail }}$.

\section{NUMERICAL SIMULATIONS}

Simulation studies are conducted to validate the effectiveness of the proposed approach in this section. Some parameters of the whole braking system are: $\mathrm{m}=75 \mathrm{~kg}, \mathrm{~J}=1.7 \mathrm{~kg} \cdot \mathrm{m}^{2}, f_{a}=0.003 \mathrm{Ns}^{2} / \mathrm{m}^{2}$. The $\mathrm{HB}$ torque is limited to $400 \mathrm{Nm}$. The maximum braking torque of $\mathrm{RB}$ is $100 \mathrm{Nm}$. The desired slip model is defined as [13] :

$$
\dot{\lambda_{d}}+10 \lambda_{d}=10 \lambda_{c}
$$

where $\lambda_{c}$ can be calculated by three point prediction method. For comparison purpose, two conventional distribution strategies, named Strategy 1 and Strategy 2, respectively, are also applied in emergency braking. Strategy 1 is to make the HB torque $\left(T_{h d b}\right)$ equal to the total required braking torque $\left(T_{t r b}\right)$ calculated by the supervisory slip controller. The small deficiencies caused by the slow dynamic characteristics of the HB system and other uncertain factors will be compensated by the RB system. On the other hand, for improving the energy recovery efficiency, Strategy 2 is to make the HB system not work until the total required braking torque exceeds the maximum torque that the RB system can provide.

In the simulations, the proposed strategies, Strategy 1, and Strategy 2 are tested under two different road conditions. First, the vehicle is running on a wet asphalt road surface with an initial speed of $30 \mathrm{~m} / \mathrm{s}$ and an initial battery SOC value of 0.5 . When pedal stroke is $70 \%$ of the maximum pedal stroke and the emergency braking is applied, the vehicle speed and wheel speed for the proposed strategy are shown in

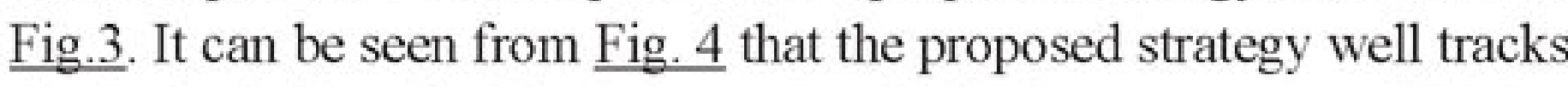
the desired slip ratio. Fig. 5 shows the whole change process of SOC during braking. Other two strategies' simulation results are summarised in Table 2. Second, the vehicle is running on a snow road surface with the same initial speed of $30 \mathrm{~m} / \mathrm{s}$ and initial battery SOC value of 0.5 . When pedal stroke is $70 \%$ of the maximum pedal stroke 
and the emergency braking is applied, the vehicle speed and wheel speed for the proposed strategy are shown in Fig.6. It can be seen from $\underline{\text { Fig. } 7}$ that the proposed strategy also well tracks the desired slip ratio. Fig. 8 shows the whole change process of SOC during braking. Other two strategies' simulation results are summarised in Table 2.

From Table 2, we can see that the proposed distribution strategy combines the advantages of Strategy 1 and Strategy 2 . When emergency braking is applied on a snow road surface, the required braking torque is small and the RB system can satisfy the required braking torque. In this situation, the proposed distribution strategy is same to Strategy 2, where all the required braking torque is provided by the RB system. Strategy 1 is different from the proposed distribution strategy and Strategy 2 that most of the braking torque is provided by the $\mathrm{HB}$ system and the RB system is only used to reduce the deficiencies between the required braking torque and the $\mathrm{HB}$ torque. So the proposed distribution strategy and Strategy 2's energy recovery is higher than Strategy 1's energy recovery. Because the regenerative system is used in all three strategies and the maximum braking torque of RB system is bigger than the required braking torque, three strategies almost achieve the same stop distance. Under the comprehensive comparison, proposed strategy and Strategy 2 are better than Strategy 1. On wet asphalt road surface, the required braking torque is bigger than the maximum braking torque of the RB system. In this case, the proposed distribution strategy is same to Strategy 1. For improving braking performance, the $\mathrm{HB}$ system starts to work at the beginning of braking in the proposed distribution strategy and Strategy 1. However, for Strategy 2, the HB braking system starts to work until the RB system's braking torque reaches to its maximum braking torque. So the braking distance of Strategy 2 is longer than the proposed distribution strategy and Strategy 1. Although Strategy 2's energy recovery is higher than the proposed distribution strategy and Strategy 1's energy recovery, the braking performance should be the priority to be considered in emergency braking. So in this situation, proposed strategy and Strategy 1 is better than Strategy 2 . From above simulation results, we can see that proposed strategy combines the advantages of Strategy 1 and Strategy 2.

Table 2. Comparison of Stopping Distance and SOC

\begin{tabular}{c|c|c|c|c|c|c}
\hline Road & \multicolumn{3}{|c|}{ Snow } & \multicolumn{3}{c}{ Wet asphalt } \\
\hline Braking & $\begin{array}{c}\text { Propose } \\
\mathrm{d}\end{array}$ & $\begin{array}{c}\text { Strateg } \\
\text { y 1 }\end{array}$ & $\begin{array}{c}\text { Strateg } \\
\text { y 2 }\end{array}$ & $\begin{array}{c}\text { Propose } \\
\mathrm{d}\end{array}$ & $\begin{array}{c}\text { Strateg } \\
\text { y 1 }\end{array}$ & $\begin{array}{c}\text { Strateg } \\
\text { y 2 }\end{array}$ \\
\hline $\begin{array}{l}\text { Distance }(m \\
\text { f }\end{array}$ & 221.5 & 221.5 & 221.5 & 57.27 & 57.27 & 57.37 \\
\hline $\operatorname{SOC}(\%)$ & 56.78 & 52.32 & 56.78 & 51.85 & 51.85 & 53.99 \\
\hline
\end{tabular}

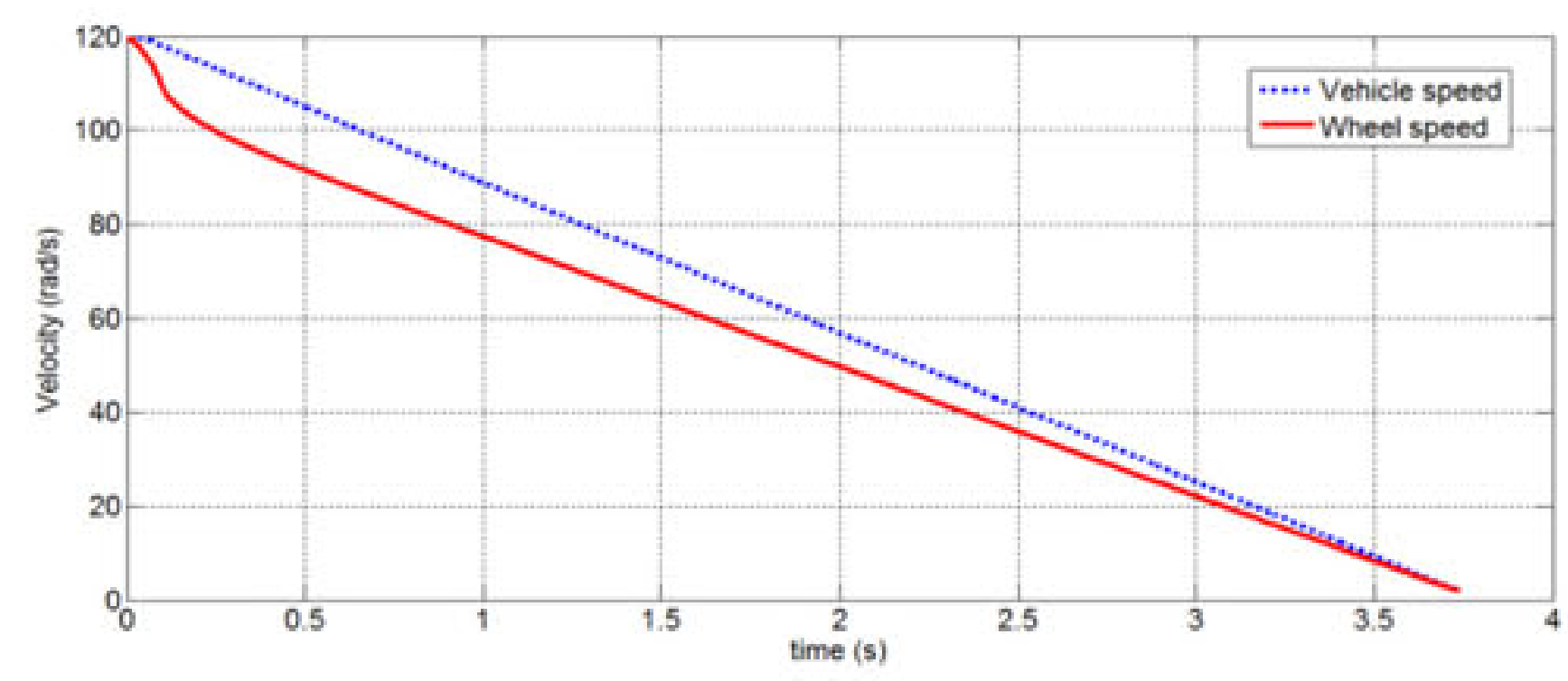

Figure 3. Vehicle speed and wheel speed with proposed strategy when driving on wet asphalt road Surface in emergency braking.

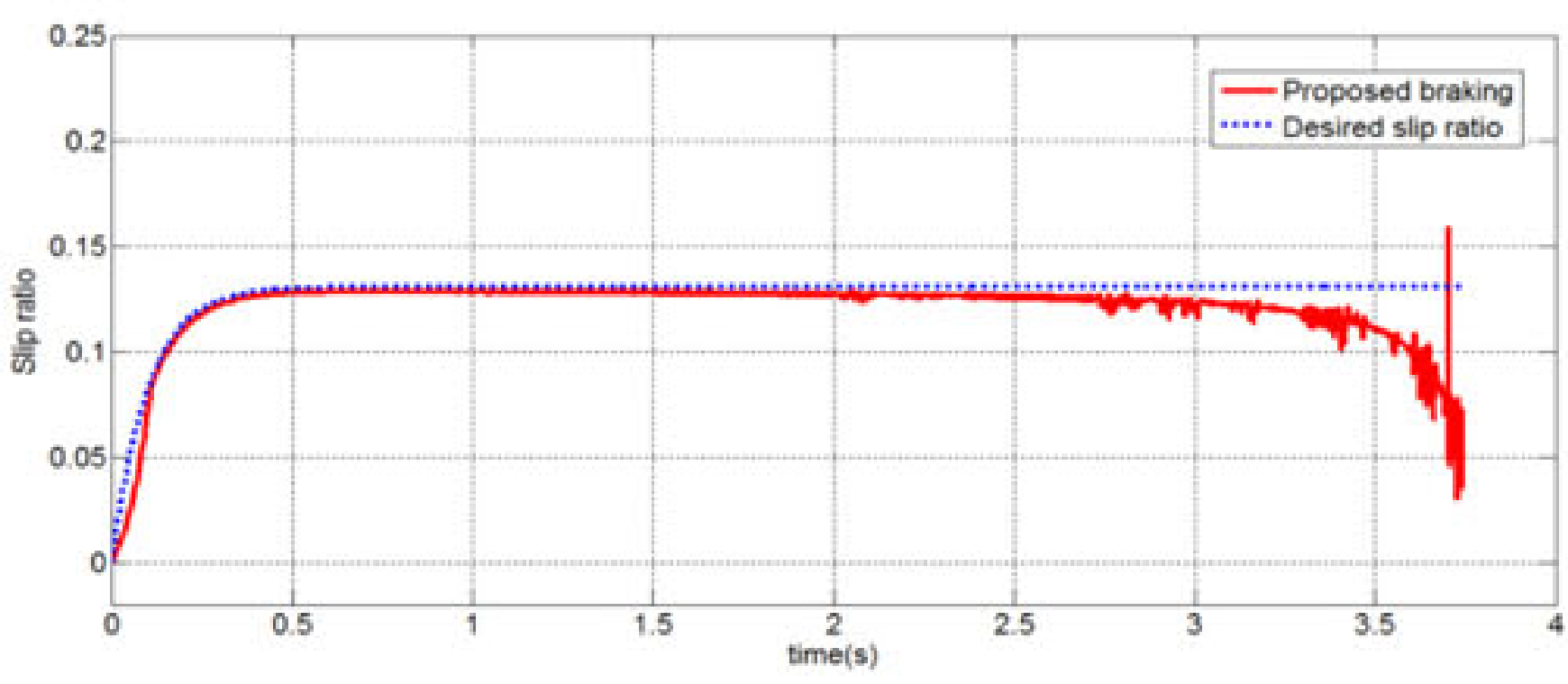

Figure 4. Wheel slip ratio when driving on a wet asphalt surface in emergency braking.

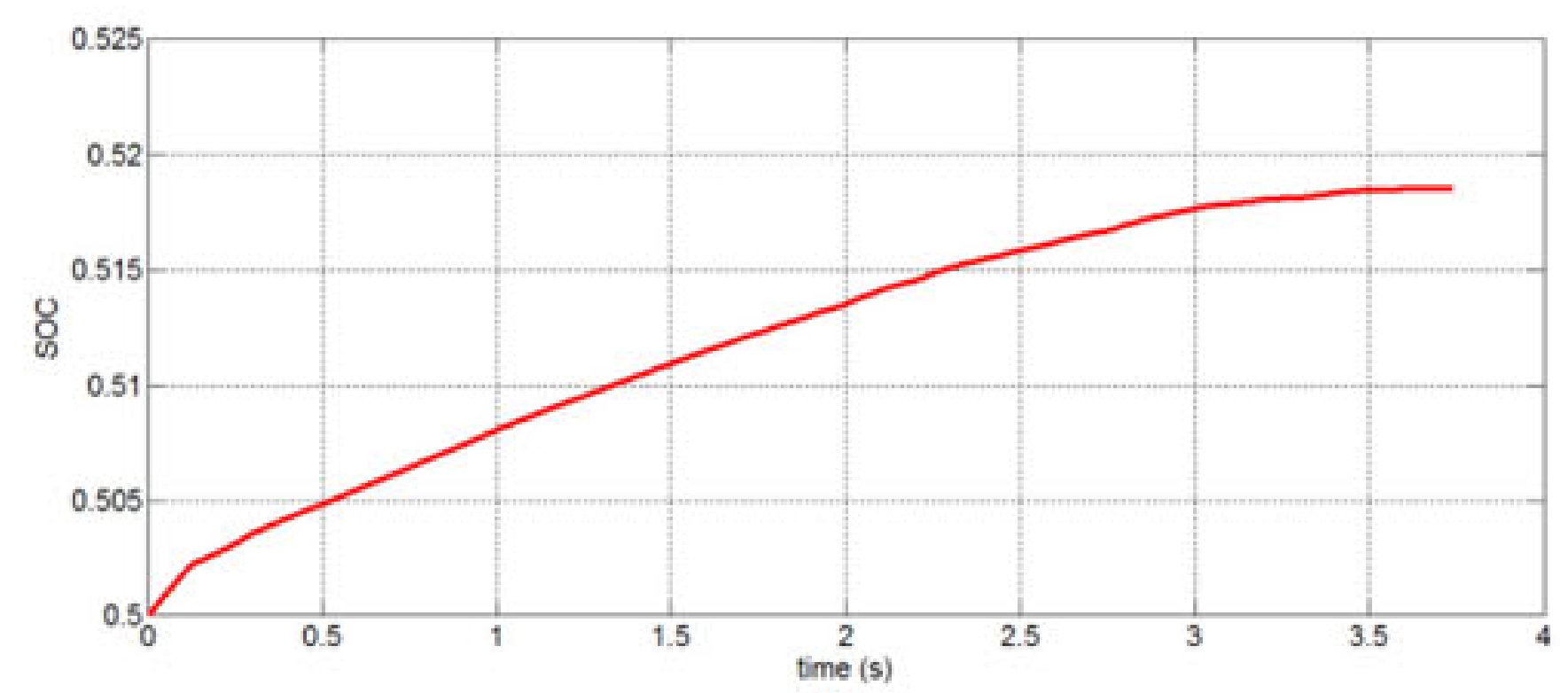

Figure 5. SOC when driving on a wet asphalt surface in emergency braking.

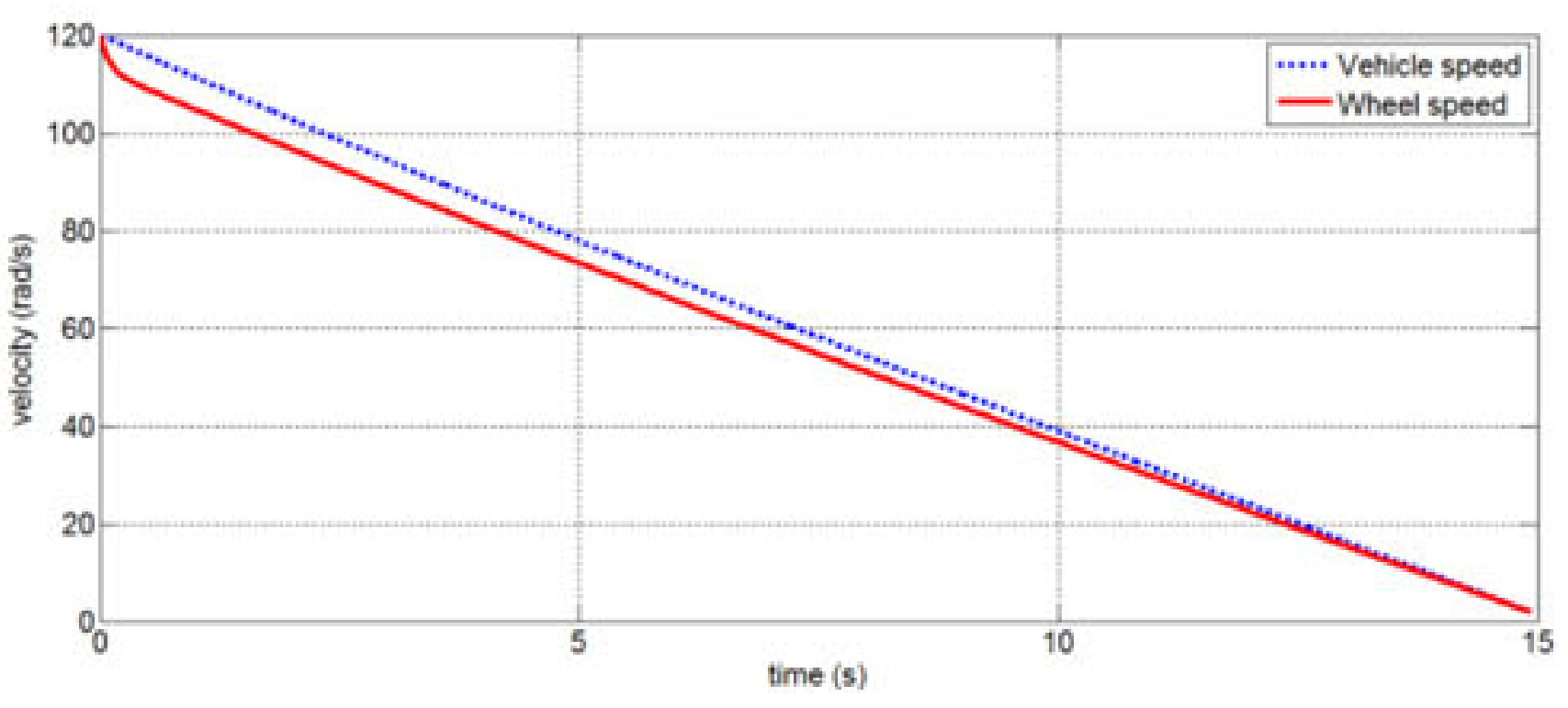

Figure 6. Vehicle speed and wheel speed with proposed strategy when driving on a snow road surface in emergency braking

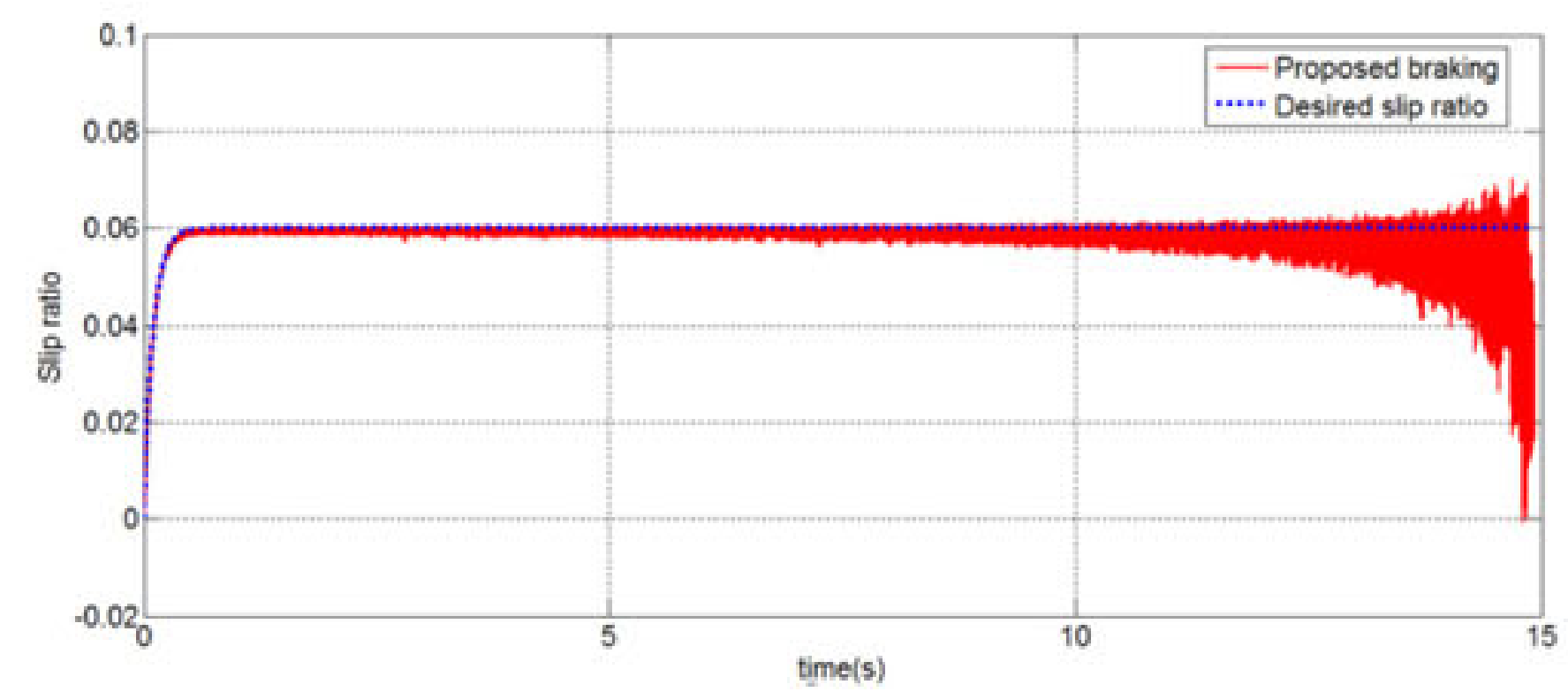

Figure 7. Wheel slip ratio when driving on a snow road surface in emergency braking.

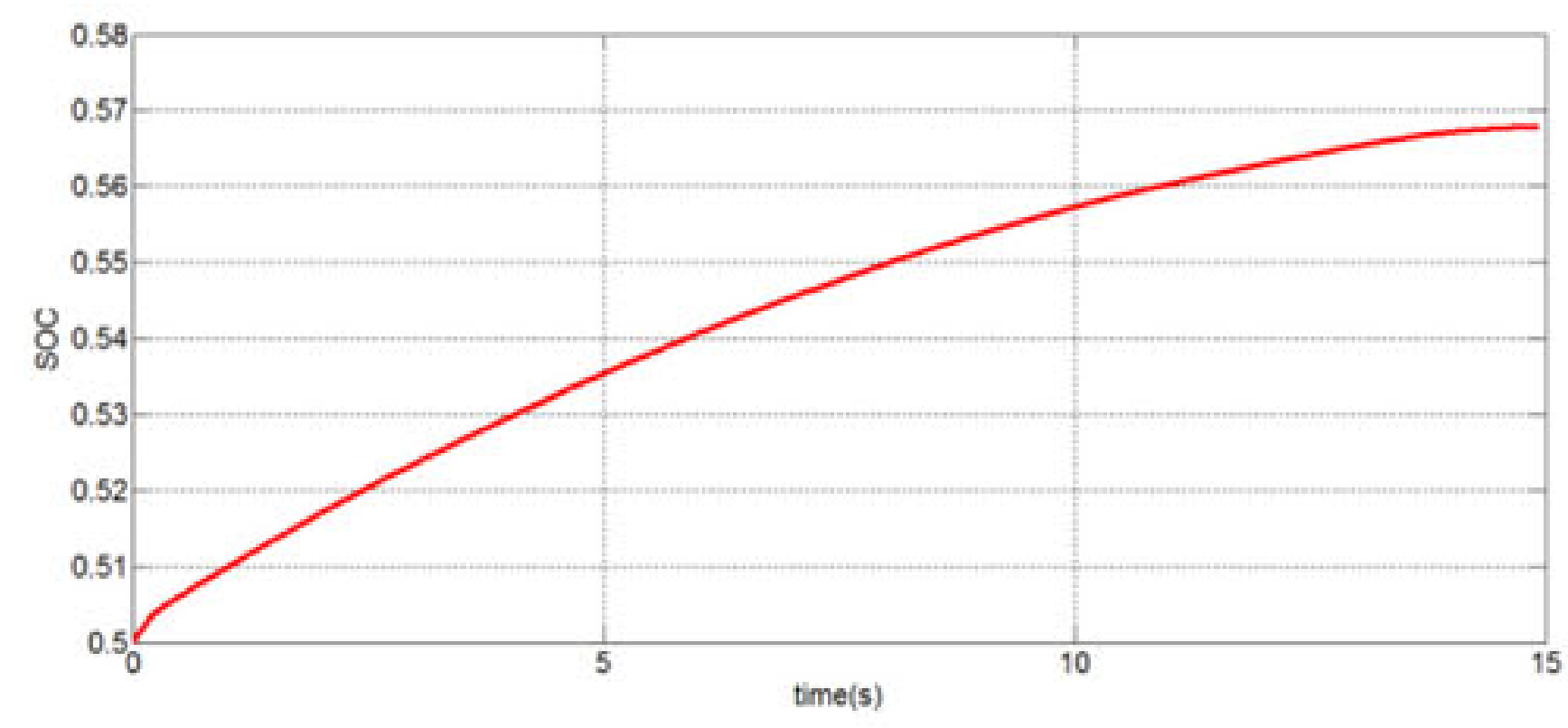

Figure 8. SOC when driving on a snow road surface in emergency braking. 
To further validate the effectiveness of the proposed approach, the braking action is now operated as normal braking when the vehicle is driving on wet asphalt road surface. The pedal stroke are given as $20 \%$ and $50 \%$ of the maximum pedal stroke, respectively. The simulation results are seen in Fig. 9 and Fig. 10. From the simulation results, we can see that the mixed braking torque output of the RB system and $\mathrm{HB}$ system can well track the required braking torque. From Fig.9, we can see that when the required braking torque is lower than the maximum braking torque of RB system, only the regeneration system works. When the pedal stroke is $50 \%$ of the maximum pedal stroke, the required braking torque is $144.7 \mathrm{Nm}$. In this situation, the required braking torque is bigger than the maximum braking torque of the RB system, and the regeneration system and hydraulic system will work together. From Fig. 10, we can see that the output torque of the RB system is $100 \mathrm{Nm}$ and the output torque of the HB system is $44.7 \mathrm{Nm}$. These simulation results confirm the performance of the proposed distribution strategy.

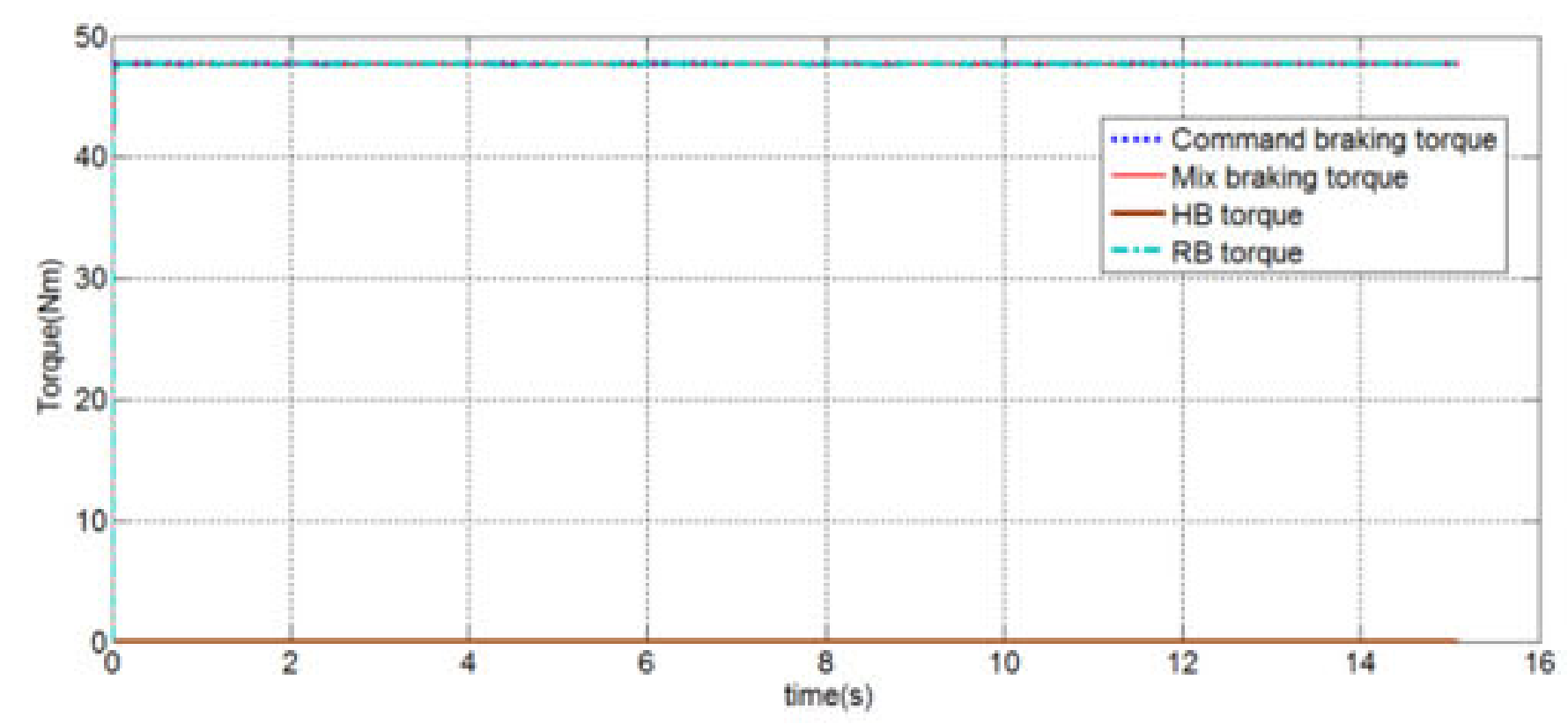

Figure 9. Various parts of the braking torque when pedal stroke is $20 \%$ of the maximum pedal stroke on wet asphalt.

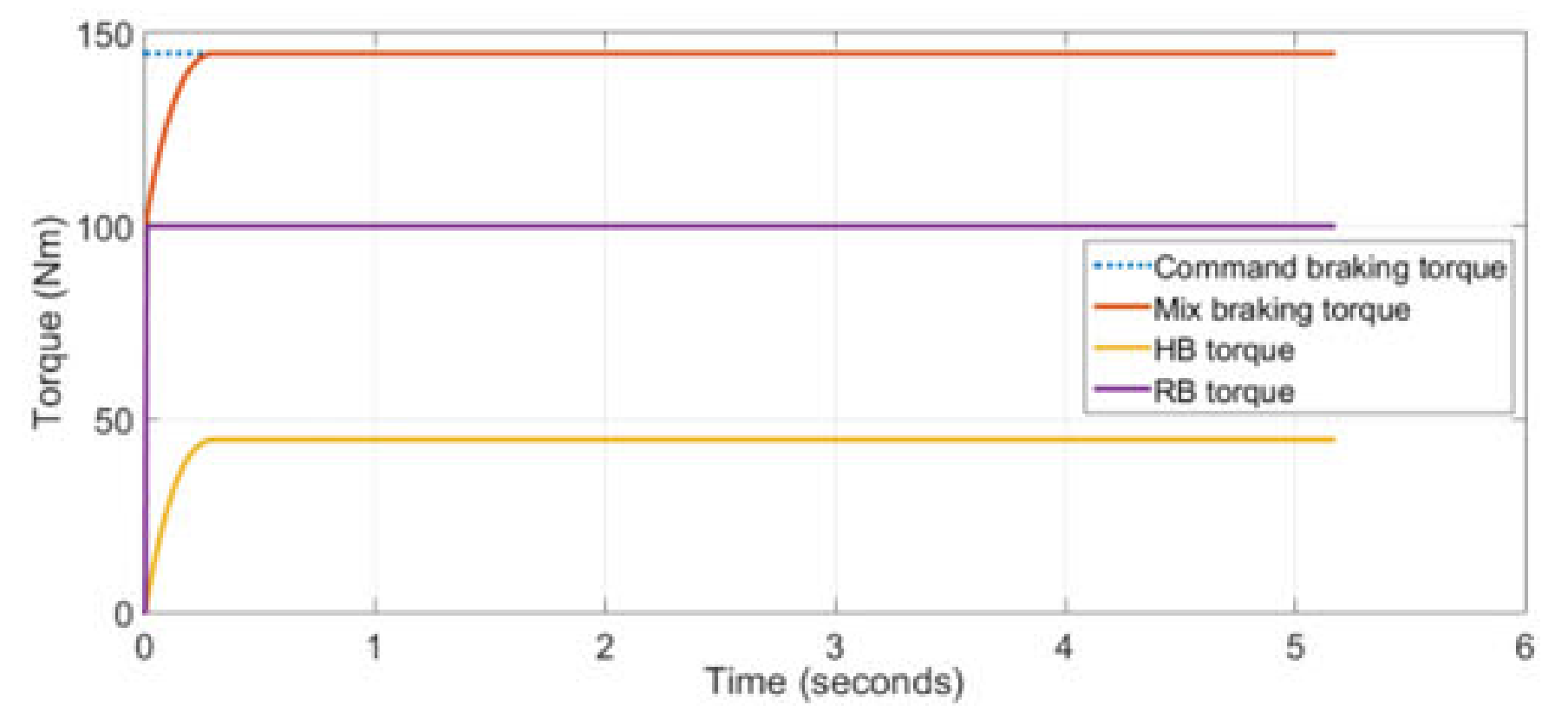

Figure 10. Various parts of the braking torque when pedal stroke is $50 \%$ of the maximum pedal stroke on wet asphalt.

In another situation, driver's command braking torque exceeds the maximum braking torque that road can provide. For example, on snow road surface, the overall maximum braking torque required for the anti-lock braking system (ABS) is about $50 \mathrm{Nm}$. When pedal stroke is $50 \%$ of the maximum pedal stroke, driver's braking intention is normal braking. However, command braking torque is 144.7 Nm and it is bigger than the maximum braking torque that road can provide. In this case, the supervisory slip controller will work. As shown in Fig.11, the mixed torque of $\mathrm{HB}$ and $\mathrm{RB}$ will not track the command torque. Supervisory slip controller will work and make wheel slip track the optimum slip ratio, as shown in Fig.12.

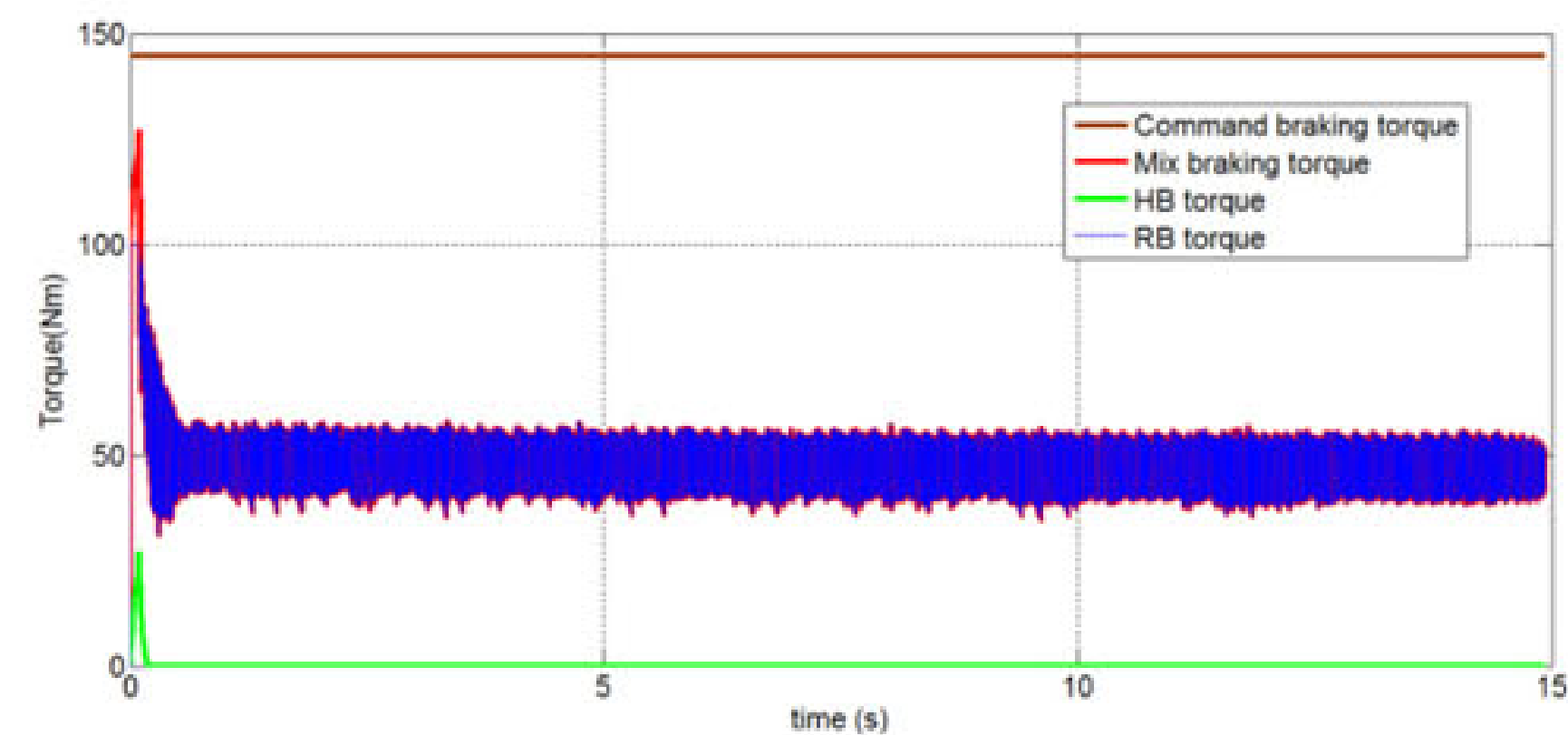

Figure 11. Various parts of the braking torque when pedal stroke is $50 \%$ of the maximum pedal stroke on snow road.

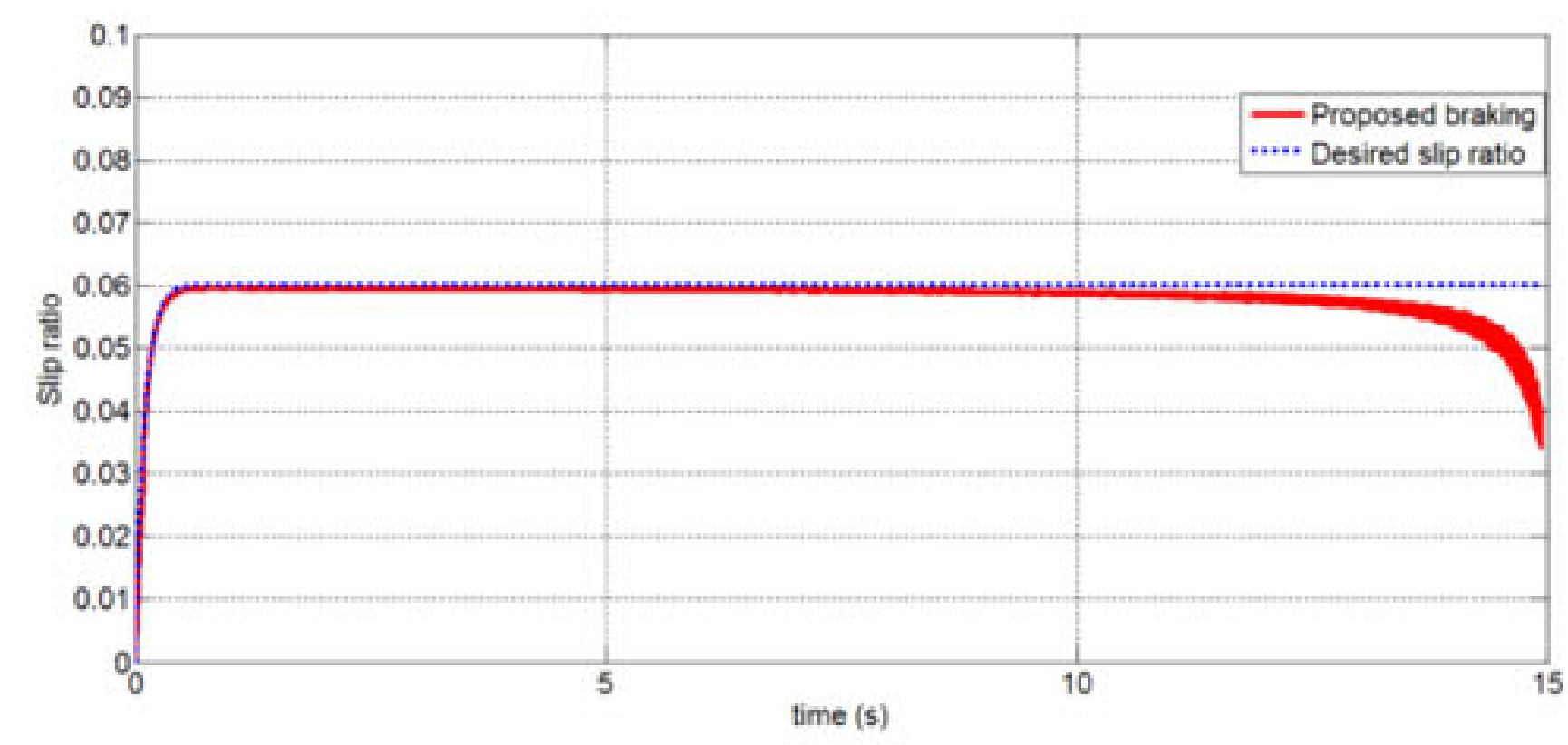

Figure 12. Wheel slip ratio when pedal stroke is $50 \%$ of the maximum pedal stroke on snow road surface.

\section{CONCLUSIONS}

In this paper, a fuzzy system is used to identify driver's braking intentions. Command braking torque can be obtained based on driver's braking intention and a pedal simulator. A three-point prediction method and a robust wheel slip controller are used to calculate the overall maximum braking torque required for the ABS. Based on driver's braking intentions, the battery state of charge (SOC), road condition and vehicle status, a new torque distribution strategy is proposed. Simulation results demonstrate that the proposed torque distribution strategy is able to obtain the shortest braking distance in emergency braking. In normal braking, supervisory slip controller can well monitor wheel slip. When command braking torque is smaller than the braking torque required for the ABS, proposed torque distribution strategy is able to well track the command braking torque and obtain as large as possible energy recovery. When command braking torque is bigger than the braking torque required for the ABS, supervisory slip controller will work and make wheel slip well track the optimal slip ratio.

\section{REFERENCES}

1. Wen-Po, C., Dejun, Y., and Hiroshi, S., "Slip-based regenerative ABS control for in-wheel-motor drive EV," Journal of the Chinese Institute of Engineers, 2015, Vol. 38, No. 2, 220-231.

2. Daegun, H., Inyong, H., Paljoo, Y., Kunsoo, H., "Development of a Vehicle Stability Control System Using Brake-by-Wire Actuators," Journal of Dynamic Systems, Measurement, and Control January 2008, Vol. 130/011008-1-9.

3. Amir, P., "Adaptive feedback linearization control of antilock braking systems using neural networks," Mechatronics 19 (2009) 767-773.

4. Nahid, E, M., and Aliakbar G., "Optimization of Bang-of-Bang TSFuzzy Based via DARLA Technique for ABS System," Journal of Advances in Computer Research Quarterly pISSN: 2345-606x eISSN: 2345-6078 Sari Branch, Islamic Azad University, Sari, I.R.Iran. 
5. Bin, W., Xiaoyu, H., Junmin, W., Xuexun, G., and Xiaoyuan, Z., "A robust wheel slip ratio control design combining hydraulic and regenerative braking systems for in-wheel-motors-driven electric Vehicles," Journal of the Franklin Institute 352 (2015) 577-602.

6. Wen-Po, C., Dejun, Y., Manabu, O., and Hironshi, S., "Integrated slip-based torque control of antilock braking system for in-wheel motor electric vehicle," IEEJ journal of industry applications 2014, Vol.3 No.4 pp.318-327.

7. Chen, L., Junzhi, Z., and Yutong, L., "Extended-Kalman-filterbased regenerative and friction blended braking control for electric vehicle equipped with axle motor considering damping and elastic properties of electric powertrain," Vehicle System Dynamics, Vol. 52, No. 11, 13721388. 2014.

8. Yuting, H., Liang, C., Yi, Y., and Shitong, Z., "Study on Braking Force Distribution Strategy for a Hydraulic Regenerative Braking System," Applied Mechanics and Materials Vols. 543-547 (2014) pp 1529-1532.

9. Rongrong, W., Chuan, H., Zejiang, W., Fengjun, Y., et al., "Integrated optimal dynamics control of 4WD4WS electric ground vehicle with tireroad frictional coefficient estimation," Mechanical Systems and Signal Processing 60-61 (2015) 727-741.

10. Wenbo, Z., Fenzhu, J., and Xiaoxu, Z., "Design and Simulation of Pedal Simulator in Brake By Wire System," Applied Mechanics and Materials Vols. 556-562 (2014) pp 1358-1361.

11. Rishabh, B., Sangram, P., and Ramesh, K, S., "Surface prediction and control algorithms for anti-lock brake system," Transportation Research Part C 21 (2012) 181-195.

12. Xiaohong, N., Fei, P., and Hang, Z., "Regenerative Braking System of Electric Vehicle Driven by Brushless DC Motor," IEEE Transactions on industrial electronics, VOL. 61, NO. 10, October, 2014.

13. Amir, P., "Adaptive feedback linearization control of antilock braking systems using neural networks," Mechatronics, Vol.19, no.5, 767-773, 2009.

14. D,P.,Y, Z.,G,L,Y., and J,W,Z., "Combined control of a regenerative braking and antilock braking system for hybrid electric vehicles," Int.J.Autom. Technol.9(6)(2008)749-757.

15. Haiping, D., Weihua, L., and Yongjun, Z., "Tracking Control of Wheel Slip Ratio with Velocity Estimation for Vehicle Anti-lock Braking System," 2015 27th Chinese Control and Decision Conference (CCDC).

16. Jiweon, K., Sungyeon, K., Hanho, S., Byoungsoo, Y., et al., "Development of Brake System and Regenerative Braking Cooperative Control Algorithm for Automatic-Transmission-Based Hybrid Electric Vehicles," IEEE Transactions on vehicular technology, VOL. 64, NO. 2 , February 2015.
17. Sun, L., "Study on driver braking intention identification and control algorithm for HEV," Master thesis, Jilin university, 2012.

18. Ricardo, M., and Marco, S., "Electrical vehicle modeling: A fuzzy logic model for regenerative braking," Expert Systems with Applications 000 (2015) 1-16.

19. Ren, H., and Donghai, H., "Nonlinear Coupling Characteristics Analysis of Integrated System of Electromagnetic Brake and Frictional Brake of Car," Mathematical Problems in Engineering Volume 2015, Article ID 928152, 14 pages. 7.doi.org/10.1155/2015/928152

\section{CONTACT INFORMATION}

Wenfei $\mathrm{Li}$

School of Electrical, Computer \& Telecommunications Engineering, University of Wollongong

Wollongong, NSW 2522, Australia

w1015@uowmail.edu.au

Haiping Du

School of Electrical, Computer \& Telecommunications Engineering, University of Wollongong

Wollongong, NSW 2522, Australia

hdu@uow.edu.au

Weihua Li

School of Mechanical, Materials and Mechatronic Engineering,

University of Wollongong

Wollongong, NSW 2522, Australia

weihuali@uow.edu.au

\section{ACKNOWLEDGMENTS}

This research was supported under Australian Research Council's Discovery Projects funding scheme (project number DP140100303).

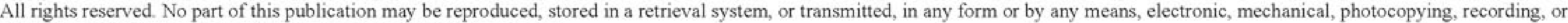
otherwise, without the prior written permission of SAE International. 